\title{
DEVELOPMENT AND STATISTICAL VALIDATION OF A SIMPLIFIED LOGISTIC LAND USE CHANGE MODEL
}

\author{
Tahmina Khan ${ }^{1}$, Michael Anderson ${ }^{2}$ \\ 1,2 Civil and Environmental Engineering Department, the University of Alabama in Huntsville, USA
}

Received 6 June 2016; accepted 5 August 2016

\begin{abstract}
Landscapes are dynamic, and the driving forces towards the societal change are related to the population growth and the lifestyle becoming increasingly urban and more mobile. The efforts to understand patterns and driving forces of urban growth or expansion have been analyzed in previous and recent studies. There is no doubt that the demand for urban land and the pressure for sustainable development will increase in any Metropolitan Area in the near future. In this study, land use change models were derived with and without variables related to urban sprawl and compared based on their statistical significance. The main goal of this paper is to propose a simplified logistic model, tested in Huntsville, AL that can highlight the probability of land use change by Traffic Analysis Zone (TAZ). Validation approach demonstrates the applications of measures of discrimination and calibration for a logistic regression model. This study can help to improve the understanding of patterns and determinants of urban growth and land expansion in Huntsville, AL. The model can be very useful to forecast the future probability of land use change and can be a substantial input in planning and decision-making process.
\end{abstract}

Keywords: land use change model, logistic regression, statistical validation, probability of land use change, traffic analysis zone.

\section{Introduction}

Landscapes are dynamic, and all the important driving forces towards the societal change are related to the population growth and the lifestyle becoming increasingly urbaner and more mobile. The three main driving forces such as accessibility, urbanization, and globalization that affected the nature and pace of the changes as well as the perception people have had about the landscape (Antrop 2005). During the last decades, high rates of change causing unsustainable development have attracted the attention of policy and planning and raised the need to understand the factors behind it. The road network shows a continuous growth and the built-up area continuous expansion, both corresponding to positive transformation rates that mean both contribute an increase in respective landscape elements (Schneeberger et al., 2007).

The uncontrolled urban expansion, a common phenomenon in the developing countries not just exerts pressure on the peripheral areas of a city but also it rapidly increases the traffic congestion in urban regions. Uncontrolled urban expansion thus land-use patterns, employment

${ }^{1}$ Corresponding author: tk0002@uah.edu 
patterns, income levels, car ownership trends, infrastructure investment, regional economic dynamics, etc. also may lead to congestion. Uncontrolled urban expansion or urban sprawl is a serious threat to urban sustainability and hence, poses a huge challenge to researchers, urban planners and policy makers to come up with remedial solutions (Mukherjee et al., 2014), (Rao and Rao, 2012).

Huntsville is the fastest growing major metro area in the state of Alabama, accounted for $34 \%$ of Alabama's Growth in population, and employment growth exceeds Alabama as a whole. The community and local business owners continue to be very positive, and the trend toward new growth is inevitable $(\mathrm{COCH}, 2015)$. The efforts to understand patterns and driving forces of urban growth or expansion have been analyzed in previous and recent studies, due to the intensified consequences of human activities on resources, open spaces, and the environment. The rapid growth can be accompanied by the disappearance of rural agricultural land, spatial fragmentation, and sustainability challenges (Luo and Wei, 2009). There is no doubt that the demand for urban land and the pressure for sustainable development will increase in Huntsville in the near future. Better understanding and managing of urban growth are critical to the development and sustainability in any city.

In this study, land use change models were derived with and without the variables related to urban sprawl and compared based on their statistical significance. The main goal is to propose a simplified logistic model for Huntsville that can highlight the probability of land use change by Traffic Analysis Zone (TAZ). The model performance was assessed through different statistical measures. Validation approach demonstrates the applications of measures of discrimination and calibration for a logistic regression model. This study can help to improve the understanding of patterns and determinants of urban growth and land expansion in Huntsville. The model can be very useful to forecast the future probability of land use change and can be a substantial input in planning and decision-making process.

\section{Literature Review}

Spatial distribution of future land use is related to demand and development supply, accessibility, spatial suitability of each piece of land, and decision-making results of different decision-makers such as households, employment, governments, land owner, and developers. It is required to know the land use variables used in recent Land Use models that can be outlined as follows:

- Bid-Rent- Analytical models based on real estate pricing, and utility maximization theory (Clay et al., 2011) o Bid rent model is a geographicaleconomic theory that refers to how the price and demand of real estate change with distance (Zhao and Peng, 2010)

- Input-Output- Analytical models based on economic flow theory (Clay et al., 2011) 
- Gravity/Logit- Analytical models founded on the concept of spatial separation (Clay et al., 2011)

- Microsimulation- Analytical models that use Monte Carlo and other simulation techniques (Clay et al., 2011)

- Rule-Based-Those models that use rulebased decision trees (Clay et al., 2011)

- An Integrated Bi-Level Model (Land Use/Transportation Model) - Cellular automata (CA) along with agent-based model capture the spatial drivers, human behaviors, and socioeconomic characteristics of land use change (Zhao and Peng, 2010)

Other variables explored were those related to the construction costs and developer choices, with respect to land use within the model. Factors with potentially significant impact on land use include (Clay et al., 2011):

- Construction economy

- Development and chronology of "dependent" land use

- Soil conditions \& Availability of utilities

- Planning \& zoning

- Municipal (or other) incentives (or disincentives) that impact development

The recent land use models/strategies that focus on human behaviors, socioeconomic characteristics, distance, price/cost and uncertainty involved in making the decision for implementing a new development (new household/new employment). It is understandable that the models above are not appropriate to address our issue while a simple model can estimate the likelihood of land use change for each TAZ in Huntsville. Moreover, models can be compared with or without variables used in scoring urban sprawl and can be applied to solve our stated problem. Because time and resources required gathering data along with the building of specific model is the major impediment, it is necessary to look at prevailing land use change model and the factors or driving forces responsible for land use change.

A simplified logistic regression has been tested and has been proposed to quantify the influences of explanatory variables on the probability of land use change (Luo and Wei, 2009), (Han et al., 2009). An integrated system dynamics and cellular automata model for urban growth assessment used socioeconomic variables (such as per capita income, migration, population and urbanization level, etc.) and the spatial factors in urban land system (such as slope, elevation, layout of road network and distance to city and sub-city centers, etc.) respectively. It can be noted that the spatial factors/ land suitability factors also play dominant roles in determining the spatial distribution of urban land growth (Han et al., 2009). A study on the probability of nonurban to urban land conversion includes the following variables shown in Figure 1 to detect the determinants of land use change using a logistic model with values of 0 (no conversion) and 1 (with conversion) (Luo and Wei, 2009). 


\begin{tabular}{lll}
\hline Variables & Type & Descriptions \\
\hline $\begin{array}{l}\text { Dependent variable } \\
\text { ChangeProb }\end{array}$ & Continuous & Probability of land use conversion \\
$\begin{array}{c}\text { Explanatory variable } \\
\text { Proximity }\end{array}$ & & \\
Dis2Hwy & Continuous & Distance to inter-city highway \\
Dis2Lard & Continuous & Distance to local artery roads \\
Dis2Rail & Continuous & Distance to railways \\
Dis2YRiver & Continuous & Distance to the Yangtze River \\
Dis2YBrid & Continuous & Distance to the Yangtze bridge \\
Dis2MCen & Continuous & Distance to major city centers \\
Dis2MNCen & Continuous & Distance to suburban centers \\
Dis2Induc & Continuous & Distance to industrial centers \\
Neighborhood & Continuous & Density of agriculture land \\
AgriDen & Continuous & Density of built-up land \\
BuiltDen & Continuous & Density of water body \\
WaterDen & Continuous & Density of forest land \\
ForeDen & & \\
\hline
\end{tabular}

Fig. 1.

Variables Used in the Land use Conversion Models Source: (Luo and Wei, 2009)

The case study analyzed in later section uses the classic multivariate statistic analysis in the modeling of land expansion. To quantify the influences of explanatory variables on probability of urban land expansion, the classic logistic regression takes the following forms (Luo and Wei, 2009), Eq. (1) and Eq. (2):

ChangeProb $_{i}=\frac{e^{\left(C+\sum_{k} \beta_{k} X_{k i}\right)}}{1+e^{\left(C+\sum_{k} \beta_{k} X_{k i}\right)}}$

$\ln \left(\frac{\text { ChangeProb }_{i}}{1-\text { ChangeProb }_{i}}\right)=\left(C+\sum_{k} \beta_{k} X_{k i}\right)$

Where: ChangeProb: the probability of landuse change to be regressed at location $i, C$ : constant, $\beta_{k}$ is the parameter for individual explanatory variable $X_{k i}(k=1,2,3, \ldots \ldots$, $n)$ that includes both socio-economic and spatial data. This classic logistic regression model adequately explains the determinants of the probability of urban land expansion from the global view (Luo and Wei, 2009).

\section{Case Study}

The Huntsville, Alabama Metropolitan Planning Area (MPA) includes all of Madison County and part of Limestone County shown in the following snapshot from Google Earth with well-defined Traffic Analysis Zones (TAZs). The metro area is around 947 square miles and has a population of 363,210 people with 156,649 households (USCB, 2010). Population and household data are available as statewide block level shapefile for 2010 (USCB, 2010) and summarized in ArcGIS to know the required values at MPA level. There are 525 Traffic Analysis Zones in the network of which 508 are internal zones, and 17 are external zones. 


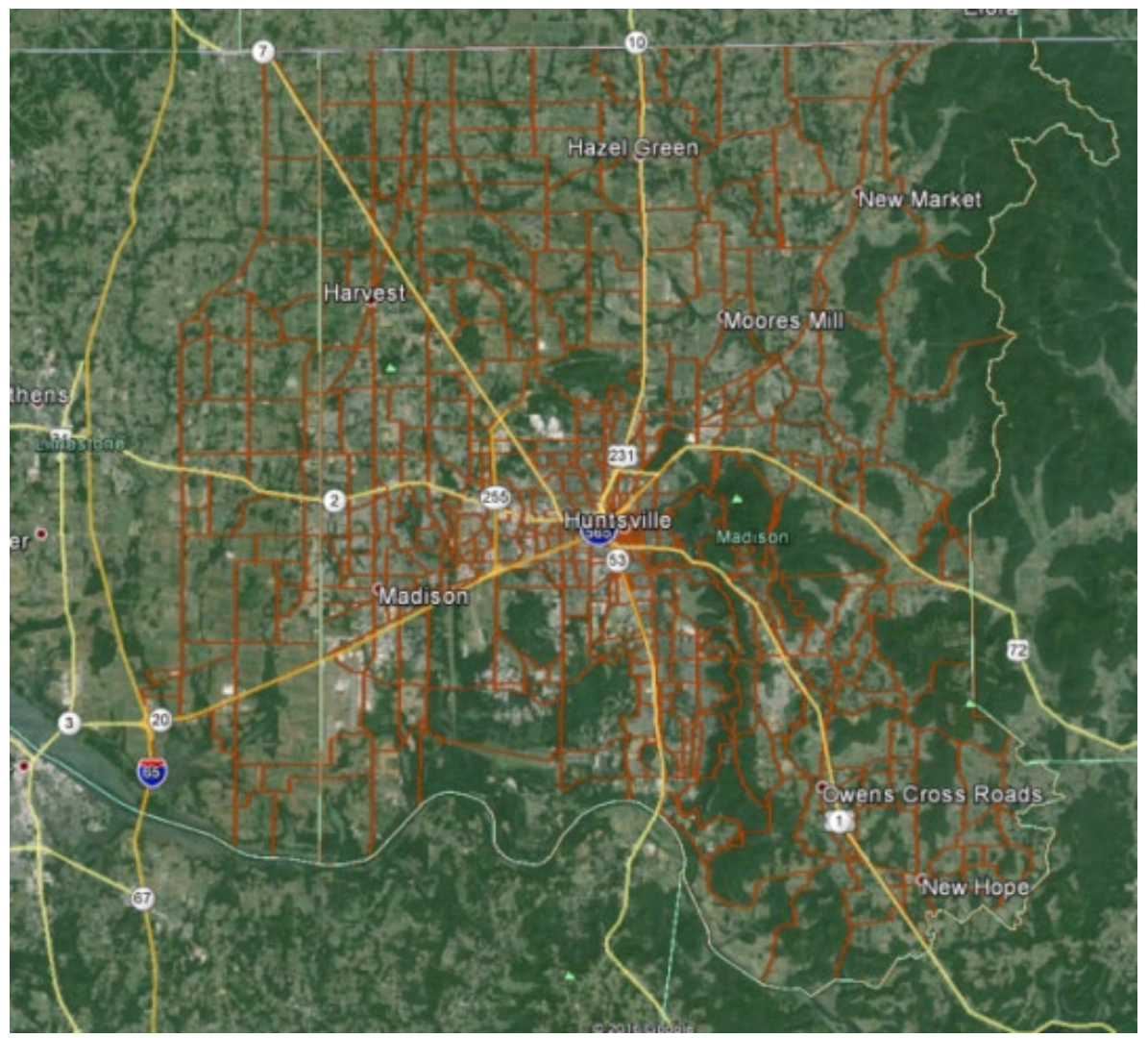

Fig. 2.

Picture of Study Area

Source: (Screenshot of Google map)

Following sections contain several essential parts to explain the response/dependent variable and explanatory variables, analysis and results, and validation process.

\section{Data/Variables}

Data were collected mostly from US census for the year 2000 and 2010. The variables can be divided into two broad categories as follows:

\subsection{Independent Variables}

The variables considered building our first logistic regression model are as follows: 


\section{Table 1}

Explanatory Variables

\begin{tabular}{|c|c|c|}
\hline Category & Variables & Source \\
\hline \multirow{4}{*}{$\begin{array}{l}\text { Proximity Variables - Nearest } \\
\text { distance to the respective item from } \\
\text { each TAZ }\end{array}$} & Distance to Major Roads in Feet & (USCB, 2010) \\
\hline & Distance to Major City Centers in Feet & (USCB, 2010) \\
\hline & Distance to River in Feet & (USCB, 2010) \\
\hline & Distance to Railways in Feet & (USCB, 2010) \\
\hline \multirow{15}{*}{$\begin{array}{l}\text { Neighborhood Percentage - Percent } \\
\text { Type of Landuse for each TAZ }\end{array}$} & Open Water & (MRLC, 2016) \\
\hline & Developed, Open Space (DO) & (MRLC, 2016) \\
\hline & Developed, Low Intensity (DL) & (MRLC, 2016) \\
\hline & Developed, Medium Intensity (DM) & (MRLC, 2016) \\
\hline & Developed, High Intensity (DH) & (MRLC, 2016) \\
\hline & Barren Land & (MRLC, 2016) \\
\hline & Deciduous Forest & (MRLC, 2016) \\
\hline & Evergreen Forest & (MRLC, 2016) \\
\hline & Mixed Forest & (MRLC, 2016) \\
\hline & Shrub/Scrub & (MRLC, 2016) \\
\hline & Herbaceous & (MRLC, 2016) \\
\hline & Hay/Pasture & (MRLC, 2016) \\
\hline & Cultivated Crops & (MRLC, 2016) \\
\hline & Woody Wetlands & (MRLC, 2016) \\
\hline & \begin{tabular}{|l|} 
Emergent Herbaceous Wetlands \\
\end{tabular} & (MRLC, 2016) \\
\hline \multirow{2}{*}{ Measures of Accessibility by TAZ } & Road Length in Miles & (USCB, 2010) \\
\hline & Road density (Miles per Sq Miles) & (USCB, 2010) \\
\hline \multirow{2}{*}{ Zonal Surface Parameters } & Mean Elevation in Meter & DEM, 2015 \\
\hline & Mean Slope Percent (45 degree is $100 \%$ ) & DEM, 2015 \\
\hline
\end{tabular}

Refined versions of the indices capture four distinct dimensions of sprawl for instance development density, land use mix, population and employment centering, and street accessibility. Compactness indices/ sprawl-like metrics for census tracts within metropolitan areas were derived through the use of following variables together with the equations (shown in Table 2 and Table 3 ) as in larger area analyzes (metropolitan area, urbanized area, and county sprawl metrics) (Ewing and Hamidi, 2014). These variables used in urban sprawl indexing were employed to develop another model that can be compared with the previous model. Because of unavailability of Walk Score related data, a new variable was introduced to measure the walkability. From any grocery shop to a TAZ block, if the nearest distance is within 1.5 miles, those values were inversed and weighted by the sum of block level population and employment as a percentage of the TAZ total to obtain Grocery/Amenity reachability index.

Employment data are accessible from the Local Employment Dynamics (LED) database that is assembled by the Census Bureau through a voluntary partnership with state labor market information agencies (Ewing and Hamidi, 2014). Workplace Area Characteristic data are collected at census block geography level and can be aggregated to any larger geography, in this case, Traffic Analysis Zone when it is required. LED data were processed for the year 2002 and 2010 
that included a total number of jobs and the number of employment by two-digit NAICS (North American Industry Classification
System) code. The data were aggregated to generate total jobs by one-digit NAICS code for every block under any particular TAZ.

Table 2

Variables Used in Measuring Sprawl Indices

\begin{tabular}{|l|l|c|}
\hline Category & Variables & Source \\
\hline \multirow{3}{*}{ Density Factor } & Gross Population density & (USCB, 2010), (ESRI, 2004) \\
\cline { 2 - 3 } & Gross Employment density & (LED, 2015) \\
\hline \multirow{4}{*}{ Mix Use Factor } & Job-Population balance & (USCB, 2010), (LED, 2015), (ESRI, 2004) \\
\cline { 2 - 3 } & Degree of Job mixing & (LED, 2015) \\
\cline { 2 - 3 } & Grocery/Amenity reachability index & (USCB, 2010), Google Earth \\
\hline \multirow{3}{*}{ Street Factor } & Intersection density & (USCB, 2010) \\
\cline { 2 - 3 } & $\%$ 4 or more way intersection & (USCB, 2010), (ESRI, 2004) \\
\cline { 2 - 3 } & Average Block Size & (USCB, 2010), (ESRI, 2004) \\
\cline { 2 - 3 } & Percent of Small blocks (<1/100 sq miles) &
\end{tabular}

\section{Table 3}

Equations to Determine New Variables ${ }^{2}$

\begin{tabular}{|l|l|}
\hline Variables & \multicolumn{1}{|c|}{ Equations } \\
\hline Gross Population density & (Total Population)/Area \\
\hline Gross Employment density & (Total Employment)/Area \\
\hline Job-Population balance & $\sum_{i=1}^{n}\left(1-\left(A B S\left(J_{i}-J P * P_{i}\right)\right) /\left(J_{i}+J P * P_{i}\right) *\left(\left(B J_{i}+B P_{i}\right) /(T J+T P)\right)\right.$ \\
\hline $\begin{array}{l}\text { Degree of Job mixing } \\
\text { Grocery/Amenity reachability } \\
\text { index (distance }<=1.5 \text { miles) }\end{array}$ & $\sum_{i=1}^{n}(1 /$ dist $) *\left(\left(B J_{i}+B P_{i}\right) /(T J+T P)\right)$ \\
\hline Intersection density & (Total Number of Intersections $\left.) /\left(P_{j} * \ln P_{j}\right) / \ln j\right) *\left(\left(B J_{i}+B P_{i}\right) /(T J+T P)\right)$ \\
\hline$\% 4$ or more way intersection & $($ Total Number of 4 way Intersections $) /($ Total Number of Intersections $)$ \\
\hline Average Block Size & Areal(Total Number of blocks) \\
\hline $\begin{array}{l}\text { Percent of Small blocks } \\
(<1 / 100 \text { square miles) }\end{array}$ & (Total Number of Small Blocks)/(Total Number of blocks) \\
\hline
\end{tabular}

Source: (Ewing and Hamidi, 2014)

\subsection{Dependent Variable}

National Land Cover Database (NLCD) serves as the definitive Landsat-based, 30 -meter resolution, land cover database for the Nation. It is a raster dataset providing a spatial reference for land surface classification (for example, urban, agriculture, forest) and can be processed to any geographic unit (Ewing and Hamidi,

${ }^{2}$ Where, $\mathrm{i}$ is the census block number, $\mathrm{n}$ is the number of blocks in the TAZ, $\mathrm{J}_{\mathrm{i}}$ or $\mathrm{BJ}_{\mathrm{i}}$ is jobs in census block, $\mathrm{P}_{\mathrm{i}}$ or $\mathrm{BP}_{\mathrm{i}}$ is residents in census block, JP is jobs per person in the metropolitan area, TJ is the total jobs in the TAZ, $\mathrm{P}_{j}$ is proportion of jobs in sector $j$, and $j$ is the number of sectors. 
2014). It provides not only land cover data (LCD) by year (2001 or 2011) but also land cover change data (LCCD) from the year 2001 to 2011. The total area for a particular type of development can be summarized at TAZ level using ArcGIS. Based on the relative probability of development or the percent developed between 2001 and 2011 can be a good estimator to identify the necessary dependent variable. Table 1 shows different types of development classified by NLCD.

It is needed to understand the raster database involved above colored features that can provide the likelihood estimates of development between 2001 and 2011 . Since it is a binary logistic regression model, the estimation of dependent variable which is either 0 or 1 must be done in a very conservative manner. For instance, DO or DL for some TAZs cannot represent the development concentration as much as $\mathrm{DM}$ and DH can. Therefore, a three level of estimation of likelihood can be considered where DO and DL can be ruled out to show the high-density development. After that, to determine the extent of development occurred, the following measures were calculated for all TAZs.

\section{Table 4}

Measures of Development

\begin{tabular}{|l|l|l|l|}
\hline Intensity & Inclusion Type & Probability of Land Use Change & Percent Change \\
\hline Low & DO+DL+DM+DH & $\begin{array}{l}\text { Ratio of Land Cover Change Data } \\
\text { (between 2001 and 2011) by TAZ to } \\
\text { that of total for the study area }\end{array}$ & $\begin{array}{l}\text { Ratio of Land Cover Change Data } \\
\text { (between 2001 and 2011) by TAZ to } \\
\text { 2001 Land Cover Data by respective TAZ }\end{array}$ \\
\hline Medium & DL+DM+DH & $\begin{array}{l}\text { Ratio of Land Cover Change Data } \\
\text { (between 2001 and 2011) by TAZ to } \\
\text { that of total for the study area }\end{array}$ & $\begin{array}{l}\text { Ratio of Land Cover Change Data } \\
\text { (between 2001 and 2011) by TAZ to } \\
\text { 2001 Land Cover Data by respective TAZ }\end{array}$ \\
\hline High & DM+DH & $\begin{array}{l}\text { Ratio of Land Cover Change Data } \\
\text { (between 2001 and 2011) by TAZ to } \\
\text { that of total for the study area }\end{array}$ & $\begin{array}{l}\text { Ratio of Land Cover Change Data } \\
\text { (between 2001 and 2011) by TAZ to } \\
\text { 2001 Land Cover Data by respective TAZ }\end{array}$ \\
\hline
\end{tabular}

At this point, it is needed to rank each TAZ based on the percentiles of above measures. Since binary logistic regression requires 0 and 1 value as the response variable, the ranking was implemented at 50 percentile value of each measure for the study area. For instance, if a TAZ value falls below 50 percentile value of a particular measure, 0 was assigned against that $\mathrm{TAZ}$ and vice versa. Overall rank was chosen by the mode of all ranks so that the ranking of six measures can be summarized into one dimension. Doing this yields a number (either 0 or 1 ) to represent the approximate likelihood of development by TAZ, that means, higher the value, more expansion can be expected by a TAZ.

\section{Analysis and Results}

This section describes model development procedure and comparison of preliminary and final models.

Binary logistic regression analysis was performed using Minitab with and without considering the variables used in measuring urban sprawl, where independent variables are from the year 2000. It involves stepwise selection of terms with a significance level of alpha of 0.15 to enter or remove from the model. Models can be named as preliminary (without sprawling variables) model and final (with sprawling variables) model. The results of both analyses can be presented as follows: 
Table 5

Deviance Table

\begin{tabular}{|l|c|c|c|l|c|c|c|}
\hline \multicolumn{4}{|c|}{ Preliminary Model } & \multicolumn{4}{c|}{ Final Model } \\
\hline \multicolumn{1}{|c|}{ Source } & DF & Adj Dev & P-Value & Source & DF & Adj Dev & P-Value \\
\hline Regression & 12.00 & 167.32 & $<0.01$ & Regression & 15.00 & 197.664 & $<0.001$ \\
\hline Error & 495.00 & 536.79 & & Error & 492.00 & 506.45 & \\
\hline Total & 507.00 & 704.11 & & Total & 507.00 & 704.11 & \\
\hline
\end{tabular}

Deviance Table (See Table 5) displays the likelihood ratio test $\mathrm{p}$-values for the coefficients. The p-value for the overall regression tests the null hypothesis that all the coefficients for predictors are equal to zero. The alternative hypothesis is that at least one of the coefficients for a predictor is not equal to zero (Minitab, 2015). Here, the p-value is close to zero. This p-value indicates that there is sufficient evidence that at least one of the coefficients is different from zero in both models. However, deviance of final model is less than that of preliminary because of additional variables, and a smaller value of deviance indicates an improvement in fit.

Model Summary (See Table 6) displays the statistics to compare how well different models fit the data. Higher values of deviance $\mathrm{R}-\mathrm{Sq}$ and adjusted deviance R-Sq indicate a better fit while smaller values of Akaike Information Criterion (AIC) indicate a better fit (Minitab, 2015). The preliminary model does not have better-fit statistics comparing to the final model.

Table 6

Model Summary

\begin{tabular}{|l|l|l|l|}
\hline \multicolumn{1}{|c|}{ Model } & \multicolumn{1}{|c|}{ Deviance R-Sq } & \multicolumn{1}{c|}{ Deviance R-Sq(adj) } & \multicolumn{1}{c|}{ AIC } \\
\hline Preliminary & $23.76 \%$ & $22.06 \%$ & 562.79 \\
\hline Final & $28.07 \%$ & $25.94 \%$ & 538.45 \\
\hline
\end{tabular}

Regression Equation displays the transformation that changes the linear equation into a predicted probability and a linear equation for predictors that includes continuous variables after eliminating insignificant variables at an alpha level of 0.15 .

Regression Equation, Eq. (3) and Eq. (4):

$$
\begin{aligned}
& P(1)=\frac{e^{Y \prime}}{1+e^{Y \prime}} \\
& Y^{\prime}=\left(C+\sum_{k} \beta_{k} X_{k i}\right)
\end{aligned}
$$

Preliminary Model

$\mathrm{Y}^{\prime}=0.02-0.000031$ Distance to Major

Roads in Feet - 0.000020 Distance to River in Feet - 7.93 Open Water + 2.63 Developed, Open Space

- 2.60 Developed, High Intensity

+ 9.17 Shrub/Scrub - 6.18 Woody Wetlands

+0.0615 Road Length in Miles

+0.02143 Mean Elevation in Meter

- 0.2254 Mean Slope Percent (45 degree is $100 \%$ ) - 0.000029 Distance to Major City Centers in Feet - 0.2510 Road density (Miles per Sq Miles) 
Final Model

$\mathrm{Y}^{\prime}=1.46-0.000025$ Distance to Major Roads in Feet - 0.000019 Distance to River in Feet - 10.09 Open Water - 5.21 Developed, High Intensity - 1.371 Cultivated Crops - 6.60 Woody Wetlands + 0.0865 Road Length in Miles + 0.02322 Mean Elevation in Meter - 0.2714 Mean Slope Percent - 0.000033 Distance to Major City Centers in Feet - 0.2211 Road density - 0.000615 Gross Population density - 0.000248 Gross Employment density + 2.514 Degree of Job mixing - 5.52 Average Block Size

The primary tool for most process modeling applications is summary measures of goodnessof-fit from a fitted model that provide information on the adequacy of different aspects of the model. The logistic regression with binary data is the area in which graphical residual analysis can be difficult to interpret as a model validation (Rana et al., 2010).

Table 7 for Goodness-of-Fit Tests displays Pearson, deviance, and Hosmer-Lemeshow goodness-of-fit tests. The goodness-of-fit tests excluding Pearson, with p-values ranging from 0.09 to 0.96 that are greater than an alpha-level of 0.05 , indicate that there is insufficient evidence to claim that the model does not fit the data adequately. Since two out of three tests fail to reject the null hypothesis of an adequate fit, it can be concluded that both models are well fitted and valid (Minitab, 2015).

Table 7

Goodness-of-Fit Tests

\begin{tabular}{|l|l|l|l|l|}
\hline \multicolumn{1}{|c|}{ Model } & \multicolumn{1}{c|}{ DF } & \multicolumn{1}{c|}{ Chi-Square } & \multicolumn{1}{c|}{ P-Value } \\
\hline \multirow{4}{*}{ Preliminary } & Deviance & 495 & 536.79 & 0.09 \\
\cline { 2 - 5 } & Pearson & 495 & 1245.24 & $<0.01$ \\
\cline { 2 - 5 } & Hosmer-Lemeshow & 8 & 2.56 & 0.96 \\
\hline \multirow{4}{*}{ Final } & Deviance & 492 & 506.45 & 0.317 \\
\cline { 2 - 5 } & Pearson & 492 & 1913.53 & $<0.001$ \\
\cline { 2 - 5 } & Hosmer-Lemeshow & 8 & 7.96 & 0.438 \\
\hline
\end{tabular}

Based on the above statistics, it can be stated that model with sprawling variables presents a better fit. It can be observed that new variables exert a great impact on urban expansion specially Average Block Size and Degree of Job Mixing. The final model effectively explains the determinants of the probability of urban land expansion. The sprawling nature of Huntsville is somewhat reflected from our logistic model.

\section{Statistical Validation}

Since the fitted model performs in an optimistic manner on the fitting sample, it can be expected to have a lower performance of the model on the validation sample. Our focus is to measure the predictive ability of a model that can accurately predict the outcome variable on new subjects. To quantify the closeness of the model's probability estimates to the correct outcome values, it is our interest to evaluate the fitting sample and the validation sample as well. In some situations, it may be possible to obtain a new sample of data from the same population and can then be used to assess the goodness-of-fit of a previously developed model. This type of assessment is called external validation which is the most 
stringent and unbiased test for the model and the entire data collection process. However, it is not possible to obtain a new independent external sample from the same population or a similar one. That leads to doing an internal validation of the model which includes several accredited methods such as datasplitting, repeated data-splitting, jackknife technique and bootstrapping, etc. The core concept of these methods is to exclude a subsample of observations, develop a model based on the remaining subjects, and then test the model in the originally excluded subjects (Giancristofaro and Salmaso, 2003).

Here, the repeated data splitting approach was implemented where data were split randomly into the fitting and validation samples without replacement by $75 \%$ and $25 \%$ respectively. The fitting sample is used to fit the model while the validation sample is used to evaluate its performance based on a two by two table known as confusion matrix. Logistic regression was performed for 10 times, and the average values were determined to propose the ultimate land use change model since each iteration is based on a different split of the original data, it results in different model coefficients, significance levels, and performance values (Giancristofaro and Salmaso, 2003). Confusion matrix outlined as follows was determined using MATLAB to validate the model (MathWorks, 2015).

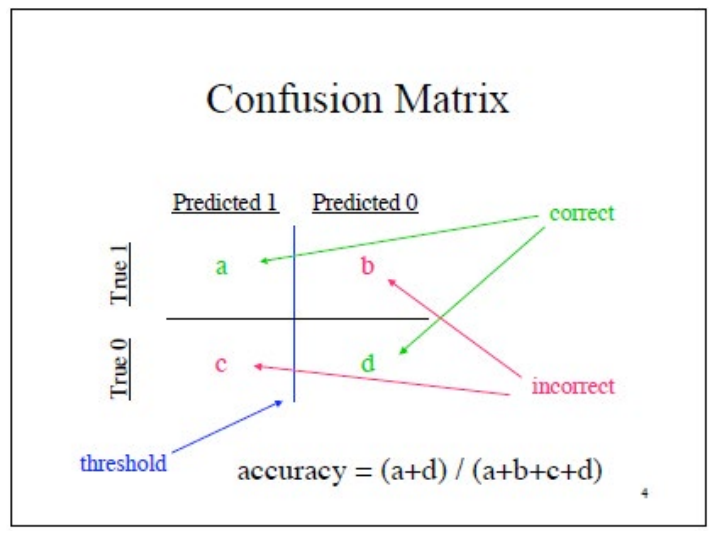

Fig. 3.

Confusion Matrix

To assess the model's quality of fit, the distributions of the estimates need to be averaged around the same values as the estimates computed on the whole original sample. If this does not happen, the model cannot be validated because of its internal instability.

\subsection{The Model's Quality of Fit}

The following table presents the parameters' estimates computed on the full sample of 508 TAZs, and the information describing the fitting distribution of their estimates of coefficients. 


\section{Table 8}

Quality of the Model's Fit: Stability of the Parameters' Estimates

\begin{tabular}{|c|c|c|c|c|c|c|}
\hline \multirow{2}{*}{ Term } & \multirow{2}{*}{ Full Model } & \multicolumn{5}{|c|}{ Model Fitted with $75 \%$ of Data - 10 Iterations } \\
\hline & & Median & $\mathbf{I Q R} / \mathbf{2}$ & $\sim$ C Var & Minimum & Maximum \\
\hline Constant & 1.46000 & 2.23000 & 0.69250 & $31.05 \%$ & -0.53000 & 3.830000 \\
\hline Distance to Major Roads in Feet & -0.00003 & -0.00003 & 0.00001 & $-27.78 \%$ & -0.00004 & -0.000015 \\
\hline Distance to River in Feet & -0.00002 & -0.00002 & 0.00000 & $-26.47 \%$ & -0.00003 & -0.000011 \\
\hline Open Water & -10.0900 & -9.75000 & 2.07000 & $-21.23 \%$ & -14.69000 & -0.390000 \\
\hline Developed, High Intensity & -5.21000 & -5.34000 & 1.27000 & $-23.78 \%$ & -6.67000 & 0.420000 \\
\hline Cultivated Crops & -1.37100 & -1.37900 & 0.32900 & $-23.86 \%$ & -2.22000 & -0.722000 \\
\hline Woody Wetlands & -6.60000 & -6.21000 & 2.01000 & $-32.37 \%$ & -9.25000 & -3.390000 \\
\hline Road Length in Miles & 0.08650 & 0.08600 & 0.00899 & $10.45 \%$ & 0.06100 & 0.116300 \\
\hline Mean Elevation in Meter & 0.02322 & 0.02005 & 0.00499 & $24.89 \%$ & 0.01230 & 0.038100 \\
\hline $\begin{array}{l}\text { Mean Slope Percent } \\
(45 \text { degree is } 100 \%)\end{array}$ & -0.27140 & -0.27590 & 0.02935 & $-10.64 \%$ & -0.35000 & -0.216600 \\
\hline $\begin{array}{l}\text { Distance to Major City Centers } \\
\text { in Feet }\end{array}$ & -0.00003 & -0.00003 & 0.00000 & $-7.35 \%$ & -0.00004 & -0.000025 \\
\hline $\begin{array}{l}\text { Road density } \\
\text { (Miles per Sq Miles) }\end{array}$ & -0.22110 & -0.23040 & 0.03030 & $-13.15 \%$ & -0.30900 & -0.191400 \\
\hline Gross Population density & -0.00062 & -0.00055 & 0.00013 & $-24.22 \%$ & -0.00081 & -0.000413 \\
\hline Gross Employment density & -0.00025 & -0.00025 & 0.00006 & $-23.67 \%$ & -0.00037 & -0.000184 \\
\hline Degree of Job mixing & 2.51400 & 2.45400 & 0.41100 & $16.75 \%$ & 1.77000 & 3.510000 \\
\hline Average Block Size & -5.52000 & -6.02500 & 1.04650 & $-17.37 \%$ & -7.66000 & -4.030000 \\
\hline
\end{tabular}

Where, IQR/2 is half of the interquartile range, $C$ Var is the ratio between $I Q R / 2$ and the Median.

The variability is moderate, indicating the presence of some degree of overfitting. As the model validates outside the available sample, the parameter's estimates computed on the full sample has been used by Eq. (1), Eq. (2) and Y' (Final Model).

Table 9 presents the overall significance of the model and the partial significance of each of the covariates. Again, both the information related to the full model and the information describing the fitting distribution was included. The overall regression model has not only a very high significance both on the full sample (overall $\mathrm{p}$-value $=0.000)$ and on the 10 Iterated fitting samples (median of the overall p-value fitting distribution $=0.000$; interquartile range $=0.000$ ) but also there is no variability between p-values. All the covariates in the model are significant an alpha value of 0.15 except one variable (Cultivated Crops). As for the quality of the model's fit, it can be concluded that the model is highly significant though this results in some degree of overfitting because of the variability in the estimates of the model's parameters over the 10 fitting samples. 
Table 9

Quality of the Model's Fit: Significance

\begin{tabular}{|c|c|c|c|c|c|c|}
\hline \multirow{2}{*}{ Item } & \multirow{2}{*}{ Full Model } & \multicolumn{5}{|c|}{ Model Fitted with $75 \%$ of Data - 10 Iterations } \\
\hline & & Median & IQR/2 & $\sim$ C Var & Minimum & Maximum \\
\hline Regression & $<0.001$ & $<0.001$ & $<0.001$ & No Change & $<0.001$ & $<0.001$ \\
\hline Distance to Major Roads in Feet & 0.051 & 0.0755 & 0.11125 & $147.35 \%$ & 0.017 & 0.343 \\
\hline Distance to River in Feet & 0.003 & 0.0265 & 0.02925 & $110.38 \%$ & $<0.001$ & 0.118 \\
\hline Open Water & 0.048 & 0.0830 & 0.15000 & $180.72 \%$ & 0.012 & 0.960 \\
\hline Developed, High Intensity & 0.004 & 0.0290 & 0.13650 & $470.69 \%$ & 0.001 & 0.881 \\
\hline Cultivated Crops & 0.110 & 0.1690 & 0.10365 & $61.33 \%$ & 0.037 & 0.451 \\
\hline Woody Wetlands & 0.011 & 0.0285 & 0.05900 & $207.02 \%$ & 0.003 & 0.312 \\
\hline Road Length in Miles & $<0.001$ & 0.0010 & 0.00200 & $200.00 \%$ & $<0.001$ & 0.016 \\
\hline Mean Elevation in Meter & 0.008 & 0.0475 & 0.04400 & $92.63 \%$ & $<0.001$ & 0.249 \\
\hline $\begin{array}{l}\text { Mean Slope Percent } \\
\text { (45 degree is } 100 \%)\end{array}$ & $<0.001$ & $<0.001$ & $<0.001$ & No Change & $<0.001$ & $<0.001$ \\
\hline $\begin{array}{l}\text { Distance to Major City Centers } \\
\text { in Feet }\end{array}$ & $<0.001$ & $<0.001$ & $<0.001$ & No Change & $<0.001$ & 0.002 \\
\hline $\begin{array}{l}\text { Road density } \\
\text { (Miles per Sq Miles) }\end{array}$ & $<0.001$ & $<0.001$ & $<0.001$ & No Change & $<0.001$ & $<0.001$ \\
\hline Gross Population density & $<0.001$ & 0.0020 & 0.00213 & $106.25 \%$ & $<0.001$ & 0.018 \\
\hline Gross Employment density & 0.002 & 0.0065 & 0.01875 & $288.46 \%$ & $<0.001$ & 0.073 \\
\hline Degree of Job mixing & 0.005 & 0.0160 & 0.02500 & $156.25 \%$ & 0.001 & 0.088 \\
\hline Average Block Size & 0.001 & 0.0025 & 0.01225 & $490.00 \%$ & 0.001 & 0.055 \\
\hline
\end{tabular}

\subsection{Generalizability of the Model}

In order for the model to be validated, model performance was assessed by comparing the actual value to the predicted one through the use of the following measures.

In all cases for determining the ability of the model to distinguish correctly the two classes of outcomes (confusion matrix), the accuracy was more than $70 \%$ for the validation sample when the cutoff point or threshold was 0.5 to classify the predicted probabilities.

A widely used statistic produced by Hosmer and Lemeshow to test the ability of a given model to calibrate, has the following format (Giancristofaro and Salmaso, 2003), Eq. (5):

$\chi^{2}=\sum_{j=1}^{10} \frac{\left(O_{j}-n_{j} P_{j}\right)^{2}}{n_{j} P_{j}\left(1-P_{j}\right)}$

Where: $n_{j}, O_{j}$, and $P_{j}$ are respectively the number of observations, the number of positive outcomes (value of 1 ) and the average predicted probabilities for the $j$ th group.

Hosmer and Lemeshow Chi-squared statistic was computed for the validation samples to measure of how close the predicted 
probabilities are to the observed rate of the positive outcome. If an observed Chisquared value less than the critical value of the Chi-squared distribution with Q-2 degrees of freedom at 0.05 alpha level, indicates good calibration (Giancristofaro and Salmaso, 2003).
Estimated Chi-square value is smaller than the critical value with 8 degrees of freedom for all iterations at an alpha level of 0.05 (that is 15.51) except for one iteration (shown in Table 10). It can be interpreted that the calibration on the validation samples is excellent.

\section{Table 10}

Amount of Misclassification and Hosmer and Lemeshow Test Statistic

\begin{tabular}{|l|c|c|}
\hline \multicolumn{1}{|c|}{ Iteration No } & Confusion Value - fraction of samples misclassified & Chi-squared statistic \\
\hline Iteration 1 & 0.213 & 7.235 \\
\hline Iteration 2 & 0.252 & 5.439 \\
\hline Iteration 3 & 0.244 & 4.961 \\
\hline Iteration 4 & 0.252 & 7.993 \\
\hline Iteration 5 & 0.283 & 7.371 \\
\hline Iteration 6 & 0.220 & 9.128 \\
\hline Iteration 7 & 0.228 & 5.071 \\
\hline Iteration 8 & 0.268 & 11.963 \\
\hline Iteration 9 & 0.276 & 15.726 \\
\hline Iteration 10 & 0.213 & 12.401 \\
\hline
\end{tabular}

\section{Conclusions}

The purpose is to build a simplified logistic model for Huntsville that can highlight the probability of land use change by Traffic Analysis Zone (TAZ). To do so, land use change models were derived with and without the variables related to urban sprawl and compared based on their statistical significance. The model with sprawling variables presents a better fit and effectively explains the determinants of the probability of urban land expansion. The sprawling nature of Huntsville is somewhat reflected from our logistic model.

It can be observed that new variables exert a great impact on urban expansion specially Average Block Size and Degree of Job Mixing. Other common variables, such as the proximity variables have minor effects on land conversion probability. Among neighborhood percentage variables, Open Water has the strongest negative effect on land conversion probability, followed by Woody Wetlands, Developed, High Intensity and Cultivated Crops. It can suggest that these variables restrict urban land expansion. Altogether, neighborhood and proximity variables imply that large-scale urban land development is not highly dependent on existing development or urban centers. Among zonal and accessibility variables, Slope and Road Density have greater influence than Road Length and Elevation. It has been found that the model with new variables is more significant (especially variables Average Block Size and Degree of Job Mixing) and should be included in developing land use change model for other location.

It can be concluded that our final model is very significant and can be used in predicting the future probability of land 
use trend since it balances between two dimensions of performance namely measure of discrimination and calibration in order to find the best trade-off.

Finally, this model can be utilized to forecast the likelihood/probability of land use change at TAZ level (such as 2020) since independent variables (such as 2010) are easily obtainable. The results can be useful in updating Travel Demand Models or Land Use Models, thus, it can help planners and decision makers in articulating and comparing different planning scenarios.

\section{References}

Antrop, M. 2005. Why landscapes of the past are important for the future, Landscape and urban planning, $70(1): 21-34$.

Clay, M.J.; White, W.L.; Holley, P. 2011. Data Development for Implementing an Integrated Land Use and Transportation Forecasting Modeling in a Medium-Sized MPO. In Proceedings of Transportation Research Board $90^{\text {th }}$ Annual Meeting.

COCH. 2015. 2015 State of the Economy-The Chamber of Commerce of Huntsville/Madison County. Available from internet: <http://www.huntsvillealabamausa.com/>.

DEM. 2015. Digital Elevation Model. AlabamaView. Accessed December 10, 2015. Available from internet: <http://www.alabamaview.org/DEM.php>.

ESRI. 2004. ESRI Data \& Maps-ArcGIS 9 Media Kit. Redlands, CA: ESRI.

Ewing, R.; Hamidi, S. 2014. Measuring urban sprawl and validating sprawl measures. Available from internet: $<$ https://gis.cancer.gov/tools/urban-sprawl/sprawlreport-short.pdf $>$.
Giancristofaro, R.A.; Salmaso, L. 2007. Model performance analysis and model validation in logistic regression, Statistica, 63(2): 375-396.

Han, J.; Hayashi, Y.; Cao, X.; Imura, H. 2009. Application of an integrated system dynamics and cellular automata model for urban growth assessment: A case study of Shanghai, China, Landscape and Urban Planning, 91(3): 133-141.

LED. 2015. Longitudinal Employer-Household Dynamics. Local Employment Dynamics. Accessed December 10, 2015. Available from internet: <http:// lehd.ces.census.gov/data/>.

Luo, J.;Wei, Y.D. 2009. Modeling spatial variations of urban growth patterns in Chinese cities: the case of Nanjing, Landscape and Urban Planning, 91(2): 51-64.

MathWorks. 2015. MATLAB and Statistics Toolbox Release 2015a. The MathWorks, Inc.Massachusetts, United States.

Minitab. 2015. Minitab Statistical Software, Release 17. Available from internet: <https://www.minitab. com/en-us/>.

MRLC. 2016. National Land Cover Database. MultiResolution Land Characteristics (MRLC) Consortium. Available from internet: <http://www.mrlc.gov/ finddata.php $>$.

Mukherjee, A.B.; Pate, N.; Krishna, A.P. 2014. Development of heterogeneity index for assessment of relationship between land use pattern and traffic congestion, International Journal for Traffic \& Transport Engineering, 4(4): 397-414.

Rana, S.; Midi, H.; Sarkar, S.K. 2010. Validation and performance analysis of binary logistic regression model. In Proceedings of the WSEAS International Conference on Environmental, Medicine and Health Sciences, 51-55. 
Rao, A.M.; Rao, K.R. 2012. Measuring urban traffic congestion-a review, International Journal for Traffic and Transport Engineering, 2(4): 286-305.

Schneeberger, N.; Bürgi, M.; Hersperger, A.M.; Ewald, K.C. 2007. Driving forces and rates of landscape change as a promising combination for landscape change research-An application on the northern fringe of the Swiss Alps, Land Use Policy, 24(2): 349-361.
USCB. 2010. Tiger/Line Shapefiles. United States Census Bureau. Available from internet: <https:// www.census.gov/geo/maps-data/data/tiger-line.html >.

Zhao, L.; Peng, Z-R. 2010. An Integrated Bi-Level Model to Explore the Interaction between Land Use Allocation and Transportation, Transportation Research Record: Journal of the Transportation Research Board, 2176(2010): 14-25.

\section{ijtte 405}

